Research Article

\title{
The Possible Protective Effects of Inegy versus Cinnamon Oil on the Aorta of Albino Rats with Experimentally Induced Hyperlipidemia
}

\author{
Moushira M. Safi, Maha W. Abou-Nazel, Fardous S. Karawya*, Amira M. Omar \\ Department of Histology and Cell Biology, Faculty of Medicine, Alexandria University, Alexandria, Egypt \\ Email address: \\ f_karawya2010@yahoo.com (F. S. Karawya)
}

To cite this article:

Moushira M. Safi, MahaW. Abou-Nazel, Fardous S. Karawya, Amira M. Omar. The Possible Protective Effects of Inegy versus Cinnamon Oil on the Aorta of Albino Rats with Experimentally Induced Hyperlipidemia. International Journal of Clinical and Experimental Medical Sciences. Vol. 1, No. 4, 2015, pp. 78-91. doi: 10.11648/j.ijcems.20150104.12

\begin{abstract}
Background: hypercholesterolemia is a predominant risk factor for atherosclerosis. The clinical complications of atherosclerosis could be suppressed when plasma lipids are lowered by hypocholesterolemic agents. The aim of this research is to assess the possible protective effect of the drug Inegy versus cinnamon oil on the histological structure of the abdominal aorta of rats with experimentally induced hyperlipidemia. Materials \& Methods: the animals were divided into 2 groups (control and experimental group). Group I (control group) was divided into: subgroup I a; received standard diet only, subgroup Ib received Inegy $10 \mathrm{mg} / \mathrm{kg}$ body weight / day orally and subgroup Ic received cinnamon oil orally. Group II (The experimental group) was divided into: subgroup II, which received a high fat high cholesterol (HFHC) diet, subgroup II b received simultaneously both HFHC diet and Inegy and subgroup II c which received simultaneously both HFHC diet and cinnamon oil. After 3 months blood samples were collected from all rats for cholesterol and triglyceride estimation and fresh specimens were taken from the abdominal aorta of each rat and processed for; light microscopic, immunohistochemical and morphometric studies. Results: Significant increase of serum cholesterol and triglyceride levels in hyperlipidemic rats (subgroup II a) was detected. Moreover, evident structural changes in the form of endothelial irregularity, focal loss and shedding of large areas of denuded endothelium were illustrated. It was associated with adhesion of mononuclear leukocytes and increased foam macrophages. Examination of histological sections of the abdominal aorta of (subgroups II $b$ and II c) showed pronounced amelioration of the structural changes depicted in the aorta of the hyperlipidemic subgroup. Conclusion: HFHC diet induced evident biochemical, histological and immunohistochemical changes in the rat aorta. It was also concluded that both Inegy and cinnamon oil offered good protection against the histopathological changes induced by HFHC diet. There were no statistical significant differences between the protective effect of both agents as regards the biochemical and morphometric results.
\end{abstract}

Keywords: Hyperlipidemia, Atherosclerosis, Inegy Drug, Cinnamon Oil, Aorta, Rats

\section{Introduction}

Lipid and lipoprotein abnormalities are extremely common in the general population. High-cholesterol diet is a major environmental contributor to an unbalanced lipoprotein metabolism. ${ }^{1,2}$

Hypercholesterolemia is a predominant risk factor for atherosclerosis. It is the major source of morbidity and mortality in the developed world. There is a positive correlation between serum cholesterol level and the risk of cardiovascular diseases. Leys et al., $2002^{3}$

There are several drugs that lower abnormally elevated plasma lipoprotein by reducing their production or enhance their removal. The reduction of elevated serum total cholesterol and low-density lipoprotein cholesterol (LDL-C) reduces the risk of coronary artery disease, resulting in a decrease in cardiovascular morbidity and mortality. ${ }^{4}$

Statins constitute the most powerful class of lipid lowering drugs widely used in medical practice. It inhibits 3-hydroxy-3-methylglutaryl coenzyme HMG-CoA reductase, which plays a central role in decreasing cholesterol production 
from the liver. It has anti-inflammatory, immunomodulatory properties and helps in plaque stabilization in atherosclerosis. ${ }^{5}$

One of the therapeutic hypocholesterolemic strategies is Ezetimibe. It is the first of the selective cholesterol absorption inhibitors, which affects exogenous cholesterol. Ezetimibe can be effectively and safely co-administered with statin. Dual inhibition of both cholesterol production and absorption provides consistently greater reductions in LDL-C compared with the single inhibition of cholesterol production afforded by statins alone. Experimental studies have demonstrated that ezetimibe synergistically reduces plasma cholesterol levels when co-administered with HMG-CoA reductase inhibitors without evidence of liver or skeletal muscle toxicity. ${ }^{4,6}$

Inegy is a drug marketed in 2005. It is a fixed dose combination tablet containing two cholesterol lowering agents with complementary mechanisms of action. Each tablet contains $10 \mathrm{mg}$ ezetimibe and 10, 20, 40, or $80 \mathrm{mg}$ of simvastatin.

Current research is directed towards finding naturally-occurring antioxidants of plant origin for managing hypercholesterolemia and lower the adverse effects associated with therapeutic drugs. ${ }^{7}$

It has been a resurgence of interest in herbal medicine capable of reducing and/or regulating serum cholesterol and triglycerides. Cinnamon is one of these herbs. It is one of the oldest herbal medicines that has been mentioned in Chinese texts. It contains Tannins condensed, phenolic compounds (4-10\%). It also contains volatile oils (up to 4\%) of cinnamaldehyde (60-80\%), eugenol (up to 10\%) and trans-cinnamic acid (5-10\%). Other constituents are calcium oxalate, coumarins, mucilage, resins, sugars and gum. It is rich in essential minerals such as manganese, iron and calcium. It is also rich in fibers. Cinnamon barks and leaves are widely used as spice and flavoring agent in food. ${ }^{8}$

Previous studies on the biochemical activities from cinnamon were mainly focused on its essential oils which included antioxidant, antimicrobial activity and anti-diarrheal activity. Moreover, cinnamon extract has a regulatory role in blood glucose level and lipids. ${ }^{9}$

In the present study, we examined the possible protective effect of the drug inegy versus cinnamon oil on the histological structure of the aorta of adult albino rats with experimentally induced hyperlipidemia.

\section{Materials \& Methods}

\subsection{Materials and Subjects}

This study was carried out on 30 adult male albino rats weighing about 100-150 gm. Their average ages were from 3-4 months. Animals were maintained under standard housing conditions, and allowed free access to standard laboratory food and water. Guidelines for care and use of animals, approved by the Animal House Center, Faculty of Medicine, University of Alexandria, were followed.

The animals were randomly divided into 2 groups as follows:
Group I: control group which was further subdivided into 3 equal subgroups, 5 animals each. Subgroup $I$ a, received standard diet, and subgroup Ib received Inegy $10 \mathrm{mg} / \mathrm{kg}$ body weight / day orally for three months. ${ }^{10,11}$ Each tablet was well dissolved in $10 \mathrm{ml}$ water and one $\mathrm{ml}$ of the solution was given to each rat weighing $100 \mathrm{gm}$. Subgroup Ic received cinnamon oil orally by orogastric tube $1 \mathrm{ml} /$ day for three months. ${ }^{12}$

Group II: experimental group which was further subdivided into 3 equal subgroups 5 animals each. Subgroup IIa received high fat high cholesterol (HFHC) diet. It consisted of a mixture of cholesterol $(2 \%)$, coconut oil $(2 \%)$, palm oil $(2 \%)$, egg yolk (2\%) and normal laboratory diet (92\%).

Subgroup II b received simultaneously both HFHC diet and Inegy as in subgroup Ib for three months and subgroup II $c$ received simultaneously both HFHC diet and cinnamon oil as in subgroup I $c$ for three months.

Cholesterol used in the experiment was purchased from Oxford Chemical Company in the form of powder. It was dissolved in coconut oil.

Inegy (ezetimibe/simvastatin) used in the experiment, was purchased commercially from the pharmacy under the commercial name "Inegy", a product of Global Napi Pharmaceuticals, Egypt. It was in the form of $10 \mathrm{mg}$ ezetimibe/10 mg simvastatin tablets. Cinnamon oil was purchased as the commercially available "natural cinnamon oil", a product of El Captain Company (CAP PHARM) for extracting natural oils, herbs and cosmetics.

At the end of the study, rats of all groups were anesthetized by ether anesthesia and blood samples were collected from the retro-orbital plexus using microcapillary technique. Serum was separated for cholesterol and triglyceride estimation. After blood collection all animals were sacrificed by decapitation and fresh specimens were taken from the abdominal aorta of each rat.

Each specimen was divided into 2 pieces:

- The first piece was fixed in $10 \%$ formal saline and processed to get paraffin sections for light microscopic examination using:

1. Haematoxylin and Eosin stained sections. ${ }^{13}$

2. Orcein stained sections. ${ }^{13}$

3. Gomori's Trichrome stained sections. ${ }^{13}$

- The second piece was cut into small piece about 0.5-1 $\mathrm{mm}$ then immersed immediately in $2.5 \%$ phosphate buffered glutaraldehyde and was processed for semithin sections examination using toluidine blue stain. ${ }^{14,15}$

Immunohistochemical study:

Avidin-Biotin complex / horseradish peroxidase (AB complex / HRp) immunostaining of smooth muscle cells using anti- $\alpha$ smooth muscle actin (anti- $\alpha$ SMA) were done and all tissues were counter stained with haematoxylin.

Anti - $\alpha$ smooth muscle actin antibody is a mouse monoclonal antibody (lab vision corporation). It reacts with the acetyl group and the first 4 amino acids on the N-terminal end of the peptide chain of alpha smooth actin of human, baboon, cow, rabbit, mouse, rat and chicken. It stained only the smooth muscles and the immunological reaction was confined to the tunica media, which was indicated by brown coloration. 


\section{Technique:}

Paraffin sections were deparaffinized and hydrated. After blocking the endogenous activity of peroxidase using $10 \%$ hydrogen peroxide the section were incubated with the primary antibody which was anti $-\alpha$ smooth muscle actin antibody. Then after washing with phosphate buffer, the secondary antibody was applied (biotinylated goat antipolyvalent). Then the slides were incubated with labelled Avidin-Biotin peroxides which binds to the Biotin on the secondary antibody. The site of antibody binding was visualized after adding Diaminobenzidine (DAB) chromogen which was converted into brown precipitate by peroxidase. ${ }^{16}$

Results: Alpha actin smooth muscle stain was as follows: $\mathrm{Ag}-\mathrm{Ab}$ reaction appeared brown. Nuclei, connective tissue appeared blue. Background appeared clear.

Morphometric study:

Thickness of tunica intima and media was measured by capture the image of each group using a 40X objective (bar $=50) \times 5$ fields with a numerical aperture of (16-bit digital camera (1280X1024 pixel). The image was viewed, recorded and measured the thickness using Olympus microscope-equipped with spot digital camera, using a computer program. (Histochemistry and Cell Biology Department, Medical Research Institute, Alex. Univ.).

\subsection{Statistical Analysis}

Statistical analysis was done using the SPSS software package version 20 .

Statistical analysis was done to obtain the mean, the standard deviation; the standard error of each mean and for comparison between the different subgroups involved in this study. ONE WAY test was used for comparison between independent samples.

\section{Results}

\subsection{General Appearance and Survival}

Observation of rats during the experimental period revealed that high fat high cholesterol (HFHC) diet was well tolerated by the rats with marked increase in the body weight. No mortality was detected in all subgroups during the study period.

At the end of the study and during dissection of the aorta there was excess fat deposition surrounding the aorta and other organs as kidney and liver in hyperlipidemic subgroup (subgroup II a) as compared with subgroup II b \& II c.

\subsection{Biochemical Results}

1) Serum cholesterol $(\mathrm{mg} / \mathrm{dl})$ in the different studied subgroups (Table 1):

Serum cholesterol level was estimated at the end of the study period (three months) in all rats. In the control group (subgroup I, a, b, c), there was no statistical difference observed in serum cholesterol. In the experimental group (subgroup II a which received HFHC diet), serum cholesterol was increased significantly in comparison to control rats (subgroup I a, b, c). In subgroup II b which received both HFHC and Inegy and subgroup II $c$ which received both HFHC and Cinnamon oil, there was a significant ameliorative effect on disturbed serum cholesterol in comparison to subgroup II a, though serum cholesterol remained higher than normal-lipidemic rats (subgroup I a, b, c). There was no statistical difference observed between both (subgroup IIb \& subgroup II c). The degree of reduction was the same with both hypolipidemic agents.

Statistical analysis:

The Data was collected and entered into the personal computer. Statistical analysis was done using Statistical Package for Social Sciences (SPSS/version 20) software.

Range, arthematic mean, and standard deviation were calculated, for more than two groups ANOVA test was used, followed by post Hoc test (Duncan method) to find the difference between each two groups. The level of significance was 0.05 .

2) Serum Triglyceride $(\mathrm{mg} / \mathrm{dl})$ in the different studied subgroups (Table 2):

Serum triglyceride level was estimated at the end of the study period (three months) in all rats.

In the control group (subgroups Ia, Ib and Ic), there was a statistical difference observed in serum triglyceride between subgroup Ia and subgroups Ib and Ic, while no significant difference was observed between the two subgroups Ib and Ic. In the experimental group (subgroup IIa which received HFHC diet), serum triglyceride was increased significantly in comparison to (subgroup Ia, Ib and Ic). Subgroup II b which received both HFHC and Inegy and subgroup II c which received both HFHC and Cinnamon oil, there was a significant ameliorative effect on disturbed serum triglyceride in comparison to subgroup II a, though serum triglyceride remained higher than normal-lipidemic rats (subgroup $\mathrm{Ia}, \mathrm{Ib}$ and Ic). There was no statistical difference observed between both (subgroup II b and subgroup II c). The degree of reduction was the same with both hypolipidemic agents.

Table 1. Serum cholesterol level (in $\mathrm{mg} / \mathrm{dl}$ ) in the six study subgroups.

\begin{tabular}{lllllll}
\hline Group & & & & & \\
\hline $\begin{array}{l}\text { Serum cholesterol } \\
\text { in mg/dl }\end{array}$ & $\begin{array}{l}\text { Subgroup 1a } \\
(\mathbf{n}=\mathbf{5})\end{array}$ & $\begin{array}{l}\text { Subgroup 1b } \\
\text { (Inegy) }(\mathbf{n}=\mathbf{5})\end{array}$ & $\begin{array}{l}\text { Subgroup 1c } \\
(\mathbf{c i n n a m o n})(\mathbf{n}=\mathbf{5})\end{array}$ & $\begin{array}{l}\text { Subgroup Iia (hyper } \\
\text { Lipidemic) }(\mathbf{n}=\mathbf{5})\end{array}$ & $\begin{array}{l}\text { Subgroup IIb Protected } \\
\text { with Inegy }(\mathbf{n}=\mathbf{5})\end{array}$ & $\begin{array}{l}\text { Subgroup II c Protected } \\
\text { with cinnamon (n=5) }\end{array}$ \\
\hline Range & $71-95$ & $72-90$ & $75-86$ & $91-170$ & $78-103$ & $80-95$ \\
Mean \pm SD & $80.4 \pm 10.14^{\mathrm{a}}$ & $80.2 \pm 8.20^{\mathrm{a}}$ & $79.2 \pm 5.02^{\mathrm{a}}$ & $119.2 \pm 30.26^{\mathrm{b}}$ & $87.8 \pm 9.83^{\mathrm{c}}$ & $86 \pm 6.52^{\mathrm{c}}$ \\
$\mathrm{F}$ & 22.81 & & & & & \\
$\mathrm{p}$ & $0.001^{*}$ & & & & & \\
\hline
\end{tabular}

The same small letters indicate that no significant difference

The different small letters indicate that there was a significant difference 


\subsection{Histological Results}

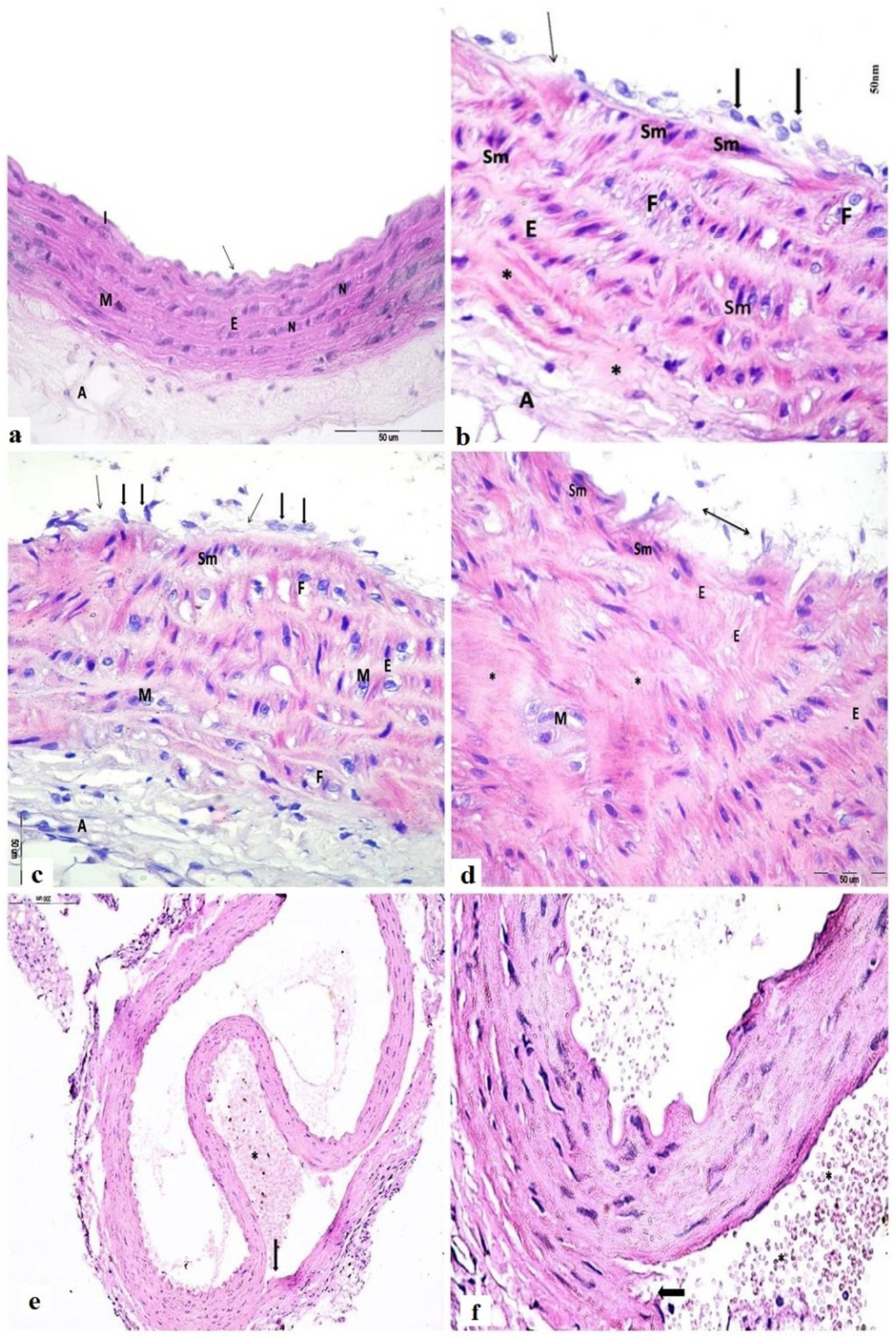

Figure 1. Photomicrograph of the abdominal aorta a; control group showing, normal architecture of the aorta (Tunica intima I with intact endothelium, ( $\uparrow)$ Tunica media M, Tunica adventitia A). b,c,d: hyperlipidemic subgroup showing, focal discontinuity of the endothelium of TI ( $\uparrow$ ) with luminal adhesion of mononuclear cells (thick arrow), marked increase in thickness with focal hyalinization in TM (*) associated with large number of foam cells (F). e,f: abdominal aorta of the same subgroup and its higher magnification showing, splitting of TM ( $\uparrow$ ) with infiltration of large number of blood cells in between the splitted wall (*). E; elastic laminae. $H \&$ E stain Mic.Mag. X400-eX100. 
Histological examination of $\mathrm{H} \& \mathrm{E}$ stained sections of the abdominal aorta of the control rats (subgroup I a, b, c) revealed the normal structure of the three tunics of the aorta; tunica intima (TI), tunica media (TM) and tunica adventitia (TA) with no significant differences between the three subgroups. The intimal surface was smooth and regular. (Fig 1 a) In comparison with the control group histological examination of $\mathrm{H} \& \mathrm{E}$ stained sections of the abdominal aorta of hyperlipidemic rats (subgroup IIa) revealed evident structural changes in the three tunics with marked increase in the perivascular deposition of fat cells. TI revealed changes ranged from the irregularity of the endothelial surface, focal loss and shedding of endothelium with luminal adhesion of mononuclear leukocyte to large area of denuded endothelium. There was focal areas of intimal thickening with sub-intimal proliferation and migration of smooth muscle cells associated with macrophages and mononuclear cells infiltration with formation of foam cells. The underlying TM showed an increase in thickness with the increase number of foam cells. Marked proliferation and disorganization of smooth muscle cells with several cells appeared in mitosis were detected (Figure $1 \mathrm{~b}, \mathrm{c}, \mathrm{d}$ ). Other sections of the same subgroup revealed splitting of TM with infiltration of blood cells in the splited wall. (Figure $1 \mathrm{e}, \mathrm{f}$ ).

Examination of $\mathrm{H} \& \mathrm{E}$ stained sections of the abdominal aorta of (subgroup II b and subgroup II c) showed, pronounced amelioration of the structural changes of the aorta in comparison to hyperlipidemic subgroup. It was found that Inegy and Cinnamon oil administration prevented to a large extent the development of atherosclerotic changes as indicated by a lesser intimal damage, foam cells formation and smooth muscle cells proliferation. (Figure $2 \mathrm{a}, \mathrm{b}$ ).
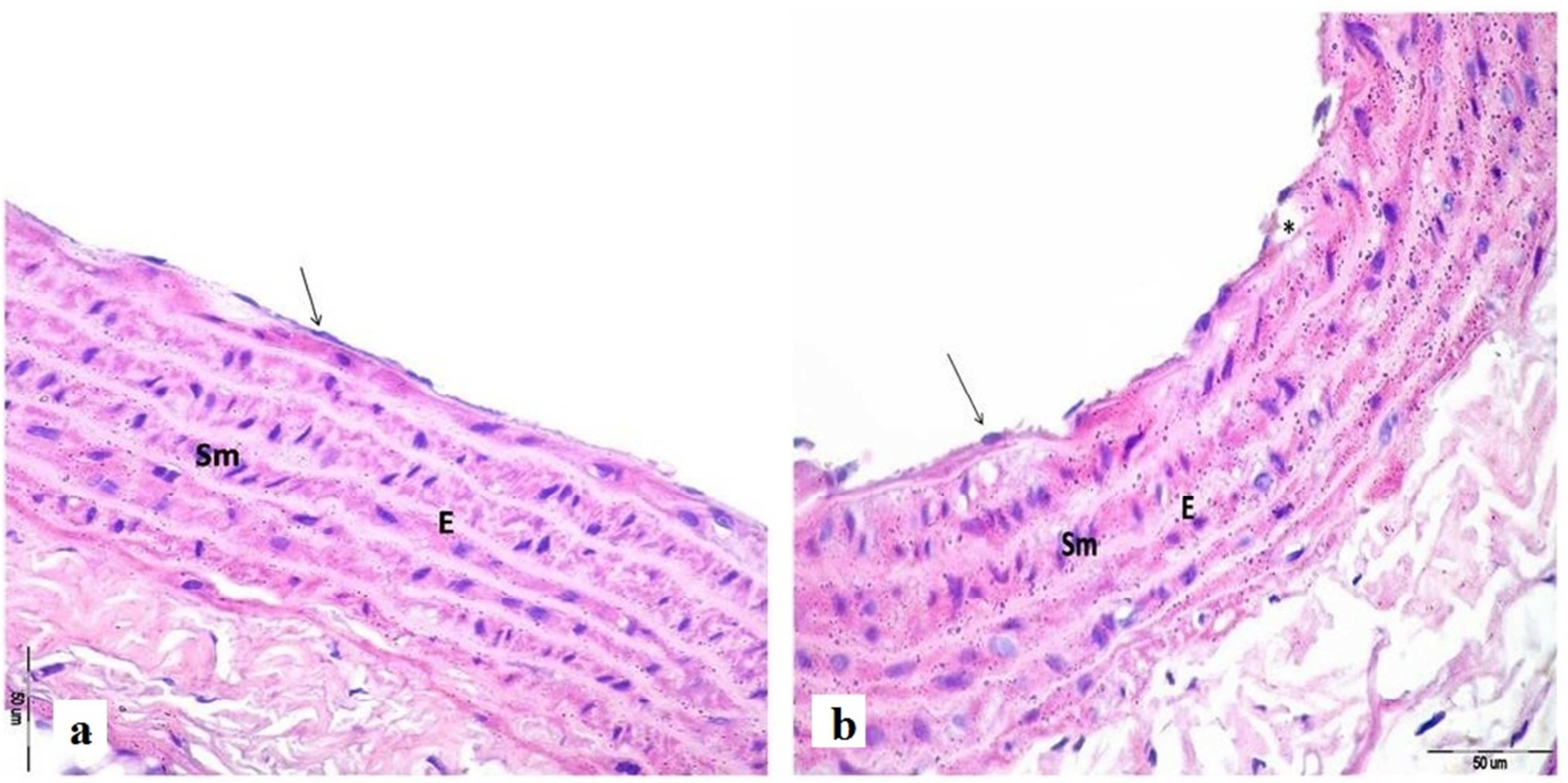

Figure 2. Photomicrograph of the abdominal aorta (protected subgroups) a: subgroup IIb - b: subgroup IIc showing, intact endothelium ( $\uparrow$ ), restoration and mild proliferation of smooth muscles (sm) in TM associated with small foci of subintimal vacuolation (*). E; elastic laminae. H\&E stain Mic.Mag. X400.

Table 2. Serum triglyceride level (in $\mathrm{mg} / \mathrm{dl}$ ) in the six study subgroups.

\begin{tabular}{lllllll}
\hline Group & & & & & \\
\hline $\begin{array}{l}\text { Serum triglyceride } \\
\text { in mg/dl }\end{array}$ & $\begin{array}{l}\text { Subgroup 1a } \\
(\mathbf{n}=\mathbf{5})\end{array}$ & $\begin{array}{c}\text { Subgroup 1b } \\
(\text { Inegy) }(\mathbf{n}=\mathbf{5})\end{array}$ & $\begin{array}{l}\text { Subgroup 1c } \\
(\text { cinnamon) }(\mathbf{n}=\mathbf{5})\end{array}$ & $\begin{array}{l}\text { Subgroup II a Hyper } \\
\text { Lipidemic }(\mathbf{n}=\mathbf{5})\end{array}$ & $\begin{array}{l}\text { Subgroup Iib Protected } \\
\text { with Inegy }(\mathbf{n}=\mathbf{5})\end{array}$ & $\begin{array}{l}\text { Subgroup IIc Protected } \\
\text { with cinnamon }(\mathbf{n}=\mathbf{5})\end{array}$ \\
\hline Range & $53-75$ & $61-77$ & $47-77$ & $72-110$ & $59-90$ & $58-85$ \\
Mean \pm SD & $63.4 \pm 9.07^{\mathrm{a}}$ & $68.8 \pm 6.18^{\mathrm{b}}$ & $67.8 \pm 12.11^{\mathrm{b}}$ & $85.2 \pm 15.27^{\mathrm{c}}$ & $70 \pm 12.23^{\mathrm{b}}$ & $70.4 \pm 12.0^{3 \mathrm{~b}}$ \\
$\mathrm{~F}$ & 28.65 & & & & & \\
$\mathrm{p}$ & $0.001^{*}$ & & & & & \\
\hline
\end{tabular}

The same small letters indicate that no significant difference

The different small letters indicate that there was a significant difference

Orcein stained sections of the abdominal aorta of the control rats revealed several continuous undulated elastic lamellae (Figure 3 a) while straightening, disorganization, discontinuation and fragmentation of elastic lamellae were noticed in orcein stained sections of hyperlipidemic rats (Figure $3 \mathrm{~b}, \mathrm{c}$ ). Abdominal aorta of rats subgroup II b \& II c revealed restoration of almost control like structure and distribution of elastic fibers. (Figure $3 \mathrm{~d}, \mathrm{e}$ ) 

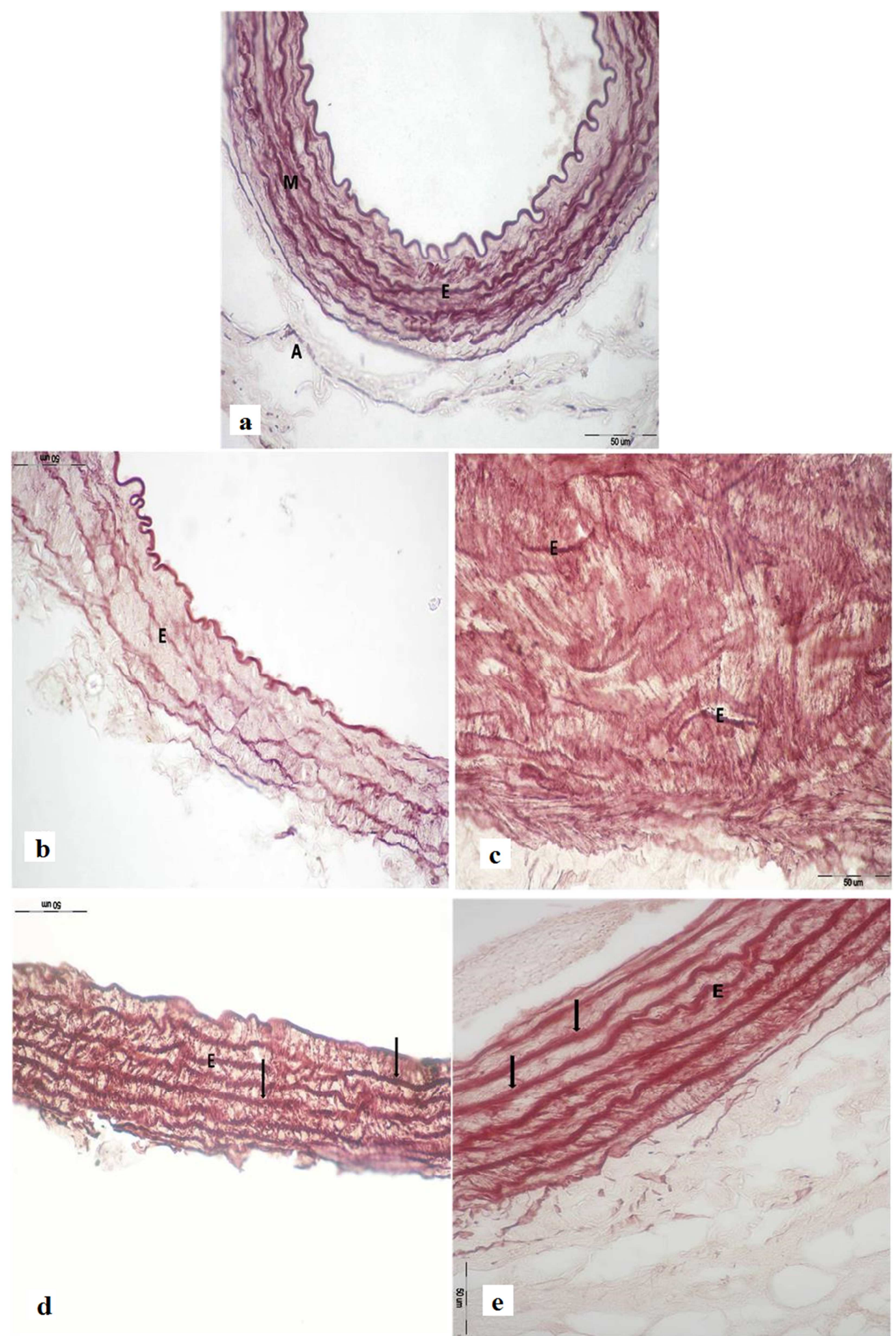

Figure 3. Photomicrograph of the abdominal aorta a: control group showing, normal fenestrated elastic laminae (E) b,c: hyperlipidemic subgroup showing, decreased number, fragmentation and complete loss of organization of elastic laminae d,e: protected subgroups d: subgroup IIb -e:subgroup IIc showing, more or less normal structure and distribution of elastic laminae, except for some straightening of the fibers( $\uparrow)$. Orcein stain Mic.Mag. X400.

As compared with normal distribution and structure of collagen fibers in the control group (subgroup I a, b, c). (Figure 4 a) Trichrome stained sections of hyperlipidemic subgroup revealed an excessive deposition of collagen fibers in the tunica media and the adventitia. (Figure $4 \mathrm{~b}, \mathrm{c}$ ) which returned to more or less control pattern in the subgroup II b \& II c. (Figure $4 \mathrm{~d}, \mathrm{e}$ ). 


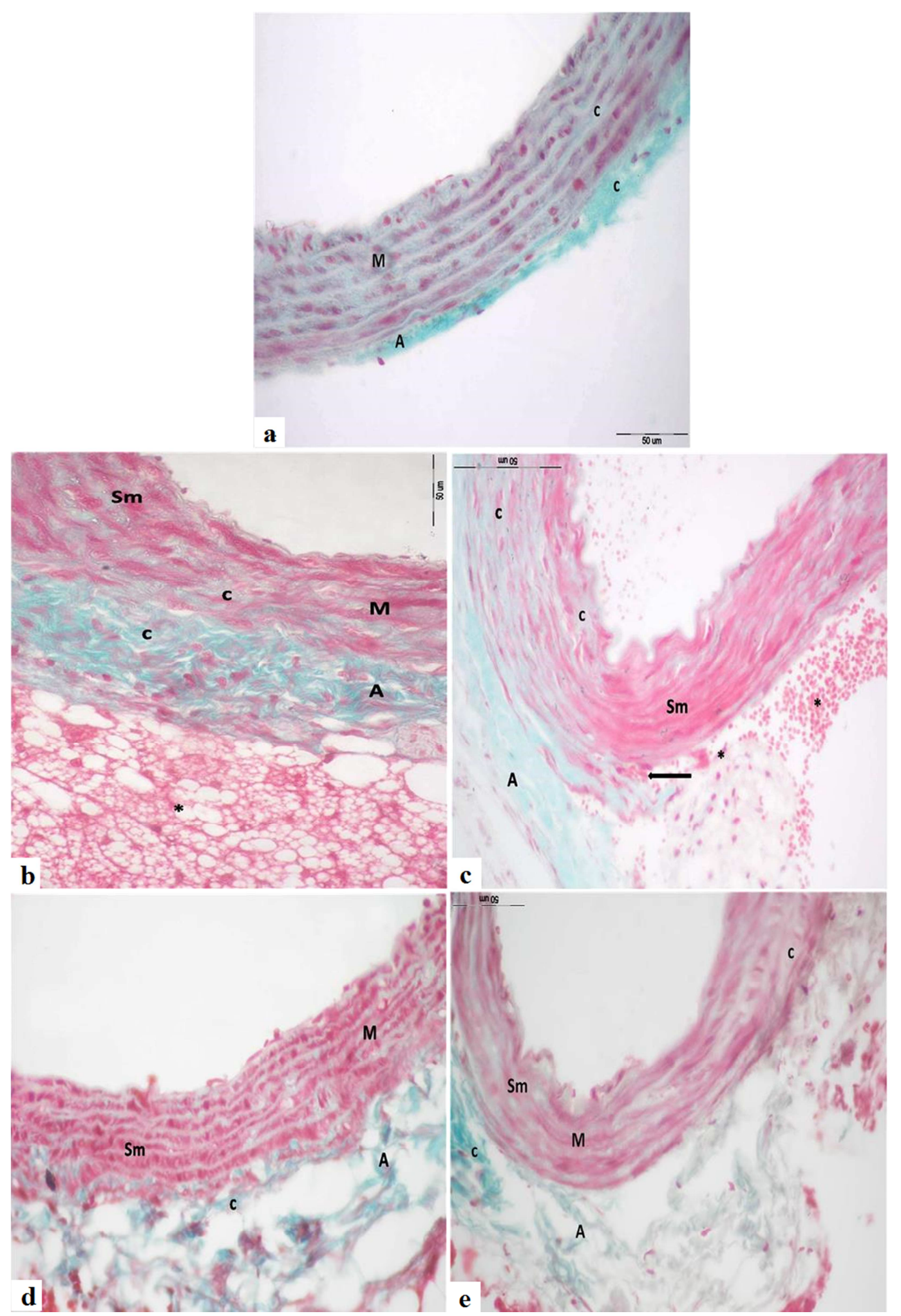

Figure 4. Photomicrograph of the abdominal aorta a: control group showing, normal distribution of collagen fibers in TM and TA. $b$, c: subgroup II a showing, increased collagen deposition(c) in TM, irregular distribution of smooth muscle cells (sm). Increased perivascular fat cells (*) is seen in b. Splitting of the wall ( $\uparrow$ with infiltration of blood cells $\left(^{*}\right)$ is seen in (c). d,e: protected subgroups d: subgroupIIb e: subgroup IIc: revealing restoration of normal pattern of collagen fibers. Gomori's trichrome stain Mic.Mag. X400.

As compared with the control group semithin sections of the abdominal aorta (Figure 5 a) the aorta of hyperlipidemic rats revealed disorganization and loss of normal structure (Figure $5 \mathrm{~b}, \mathrm{c}$ ) which returned to normal pattern in (subgroup II b \& II c). (Figure $5 \mathrm{~d}, \mathrm{e}$ ). 
Moushira Safi et al.: The Possible Protective Effects of Inegy versus Cinnamon Oil on the Aorta of Albino Rats with Experimentally Induced Hyperlipidemia

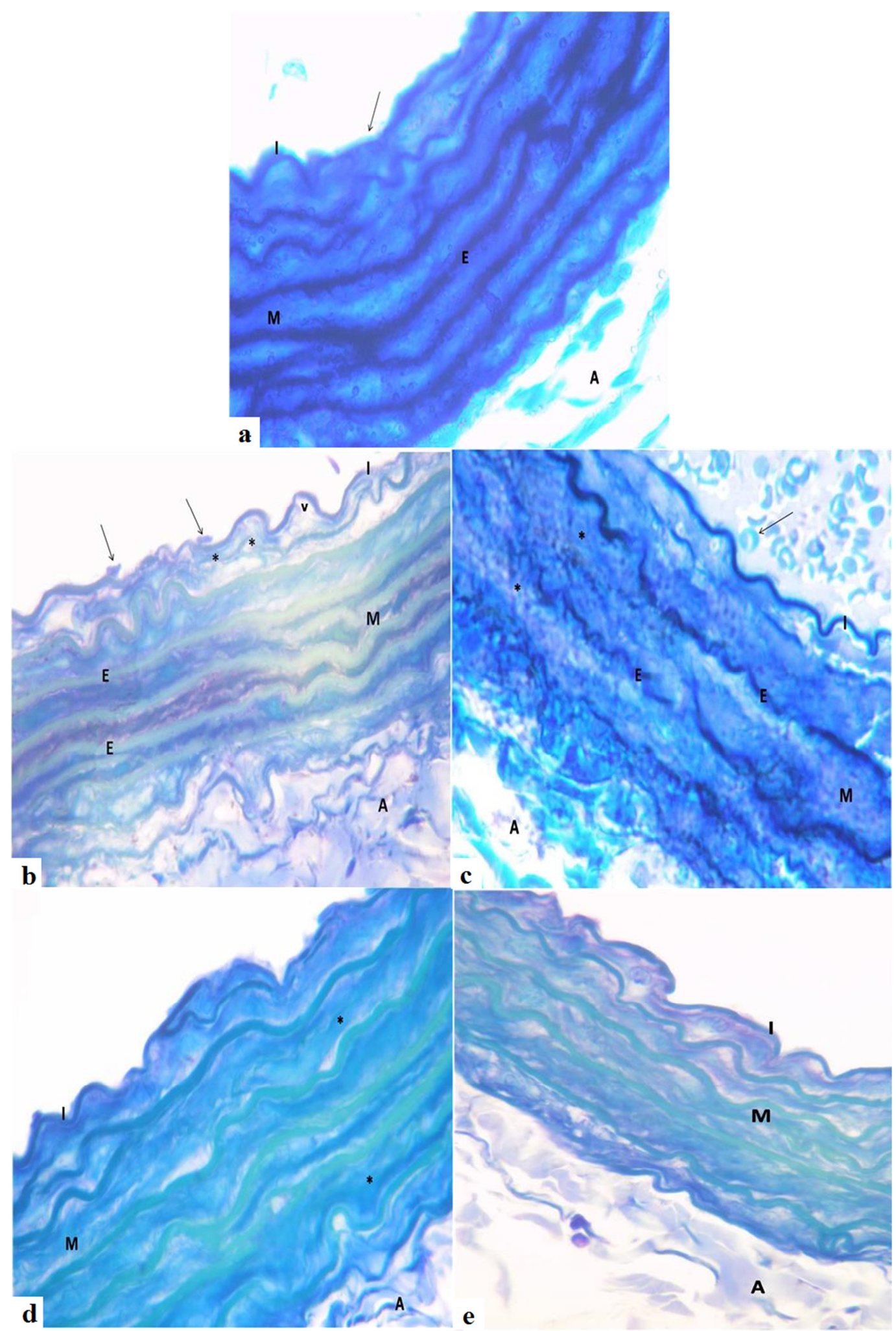

Figure 5. Photomicrograph of a something section of the abdominal aorta a: control group showing regular endothelium ( $\uparrow$ ) and normal distribution of elastic laminae (E). b,c; subgroup II a revealing luminal adhesion of mononuclear cells ( $\uparrow)$, subendothelial vacuolation (*) and disrupted elastic laminae (E) associated with thick tunica adventitia A. $d$, e: protected subgroups showing, restoration of nearly normal control image except for some hyalinization (*) seen in d. Toluidine blue stain Mic. Mag. X1000.

Proliferation of smooth muscles in H\&E stain went hand in hand with immunohistochemical results which revealed increased intensity of anti- $\alpha$ SMA reaction in hyperlipidemic rat aorta (subgroup II a) (Figure 6 b, c) which returned to normal reaction in (subgroup II b \& II c). (Figure 7 a, b, c, d). 


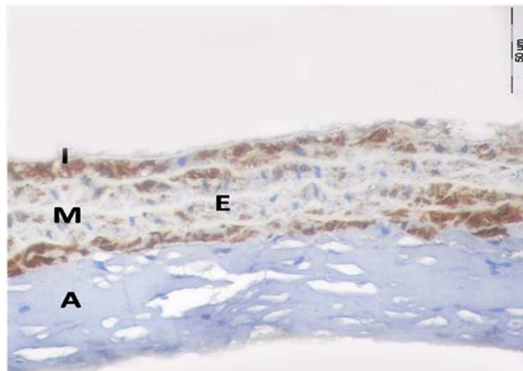

a

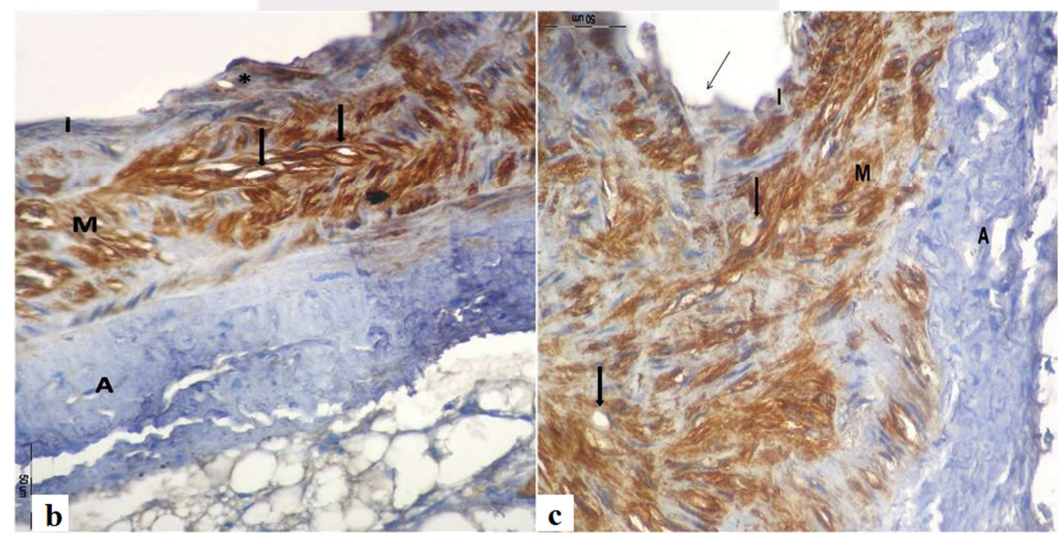

Figure 6. Photomicrograph of the abdominal aorta a: control group showing +ve immune-reactivity for anti- $\alpha$ smooth muscle actin demonstrated by brown coloration of the smooth muscle cells in the tunica media $(M) . b, c$ : hyperlipidemic subgroup showing, increased intensity of the $+v e$ immunoreactivity of anti- $\alpha$ smooth muscle actin in smooth muscle cells( $\uparrow$ ) of the tunica media (M). (Anti- $\alpha$ SMA, Mic. Mag. $\times 400)$.
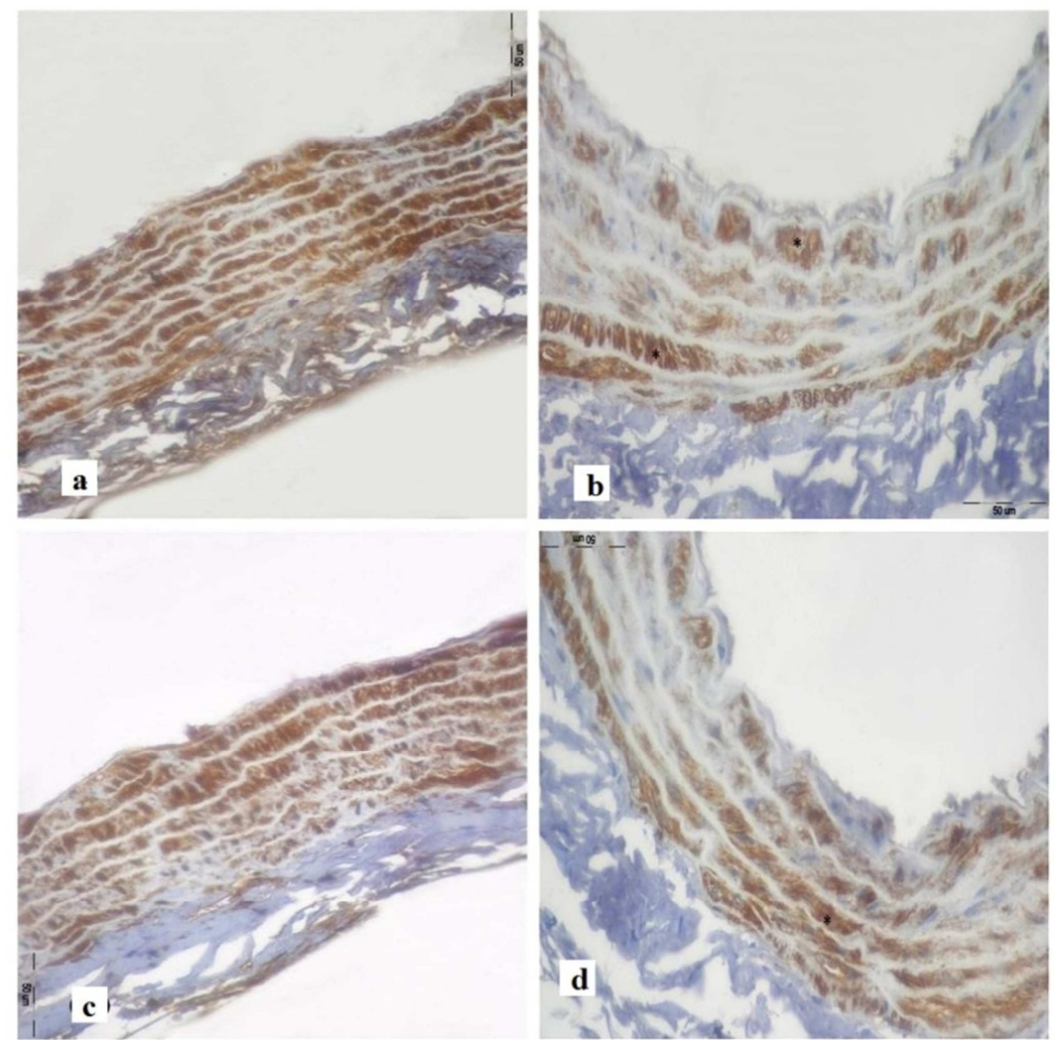

Figure 7. A Photomicrograph of rat abdominal aorta of the protected subgroups $a, b$ : subgroup II b,c,d: subgroup IIc showing restoration of normal architecture with mild focal increased activity of the +ve immunoreactivity of anti- $\alpha$ smooth muscle actin in smooth muscle cells $\left(^{*}\right)$ in the tunica media (M). (Anti- $\alpha$ SMA, Mic. Mag. × 400). 
Whereas morphometric study, revealed a significant increase in thickness of tunica intima and media in the hyperlipidemic subgroup (subgroup II a) in comparison to control rats. While in both (subgroup II b \& II c), there was significant reduction in thickness of tunica intima and media in comparison to subgroup II a (table 3). There were no significant differences between the two subgroups IIb and IIc as regards the thickness of tunica intima and media.

Table 3. Thickness of tunica intima and media (pixel) in the six study subgroups.

\begin{tabular}{lllllll}
\hline & Subgroup Ia & Subgroup Ib & Subgroup Ic & Subgroup IIa & Subgroup II b & Subgroup II c \\
\hline 1 & 361.5 & 491.64 & 444.07 & 611.9 & 573.91 & 592.7 \\
2 & 379.62 & 409.74 & 431.83 & 951.75 & 594.87 & 629.13 \\
3 & 389.17 & 465.54 & 440.32 & 729.86 & 631.63 & 794.71 \\
4 & 388.2 & 458.6 & 452.6 & 790.9 & 740.61 & 795.65 \\
5 & 379.2 & 409.8 & 436.5 & 711.51 & 742.62 & 585.6 \\
Min & 361.5 & 409.74 & 431.83 & 611.9 & 573.91 & 795.6 \\
Max & 389.17 & 491.64 & 452.6 & 951.75 & 742.62 & $679.558^{\mathrm{d}}$ \\
Mean & $379.538^{\mathrm{a}}$ & $447.064^{\mathrm{b}}$ & $441.064^{\mathrm{b}}$ & $759.184^{\mathrm{c}}$ & $656.728^{\mathrm{d}}$ & \\
S.D. & 11.11 & 36.20 & 7.89 & 125.41 & 80.20 & 106.83 \\
F & 19.65 & & & & & \\
P & $0.0001^{*}$ & & & & & \\
\hline
\end{tabular}

The same small letters indicate that no significant difference

The different small letters indicate that there was a significant difference

\section{Discussion}

In the present study the successful induction of hyperlipidemia was detected by the significant increase of serum cholesterol and triglyceride in hyperlipidemic rats. These results with some difference were in agreement with other studies conducted by Shehata et $\mathrm{al}^{17}$ and Beshbishy et $\mathrm{al}^{18}$ which showed increased atherogenic indices with experimentally induced atherosclerosis by high fat diet. ${ }^{19,20}$

In the current study, light microscopic examination of $\mathrm{H} \& \mathrm{E}$ and semithin stained sections of the aorta of the hyperlipidemic subgroup revealed evident structural changes involving the whole wall. Endothelial changes ranged from irregularity, focal loss, shedding of endothelium to large areas of denuded endothelium. It was associated with adhesion of mononuclear leukocytes and migration of blood cells with increased permeability of endothelium as detected by increased macrophages and its lipid content in the form of increased foam cells. These findings were in agreement with Shumkovska et $\mathrm{al}^{19}$ who reported abnormalities of the endothelium of the aorta of HFHC diet fed rats with appearance of foam cells and areas of thin plaque with infiltration of inflammatory cells. These findings were also consistent with Castillo et $\mathrm{al}^{21}$ who noticed adhesion and infiltration of macrophages and mononuclear cells to the intima and appearance of foam cells in the thoracic aorta of rats fed on atherogenic diet.

Several studies attributed these changes to oxidative stress. The increased production of ROS reduces the production and consequently the bioavailability of NO, which is secreted by endothelial cells, leading to vasoconstriction, platelets aggregation and adhesion of neutrophils to the endothelium. ${ }^{22}$, ${ }^{23}$ A shift in oxidative status with a decrease in NO and an increase in oxygen radicals may underlie the abnormal vascular function in hyperlipidemia. ${ }^{24}$ The net result of combined oxidative and nitrosative stress is a pro-inflammatory phenotype that is manifested as enhanced leukocyte trafficking and increased vascular permeability. ${ }^{25,26}$

Oxidative stress by hydrogen peroxide $\left(\mathrm{H}_{2} \mathrm{O}_{2}\right)$ increases phosphorylation of tyrosine kinases, which leads to stronger binding of neutrophil cells to the endothelium and alteration of vessel permeability. It also leads to production of transcription factors such as nuclear factor IB (NF-IB) and activator protein 1 (AP-1) which participates in the expression of adhesion molecules such as vascular cellular adhesion molecules- 1 (VCAM- 1), intracellular adhesion molecules- 1 (ICAM-1), E-selectin and other cytokines. ${ }^{23,26}$ This is in accordance with our results which revealed luminal adhesions of leukocytes to the endothelium of the aorta in hyperlipidemic rats (subgroup IIa).

In the current study, light microscopic examination of the hyperlipidemias subgroup revealed intimal thickening, a subendothelial collection of vacuolated cells some of them appeared around cholesterol crystals. Pronounced increased amount and migration of vascular smooth muscle cells (VSMCs) were found. These findings went hand in hand with Kapoor et $\mathrm{al}^{27}{ }^{27}$ Castillo et $\mathrm{al}^{21}$ as well as with Deepa et $\mathrm{al}^{25}$, who described foam cells as a significant event in atherogenesis.

In the current work, light microscopic examination of the hyperlipidemic subgroup depicted thickening of the media, which was also manifested in the morphometric study. It could be attributed to proliferation of VSMCs, excess deposition of collagen and excess production of extracellular matrix (ECM). These went in agreement with Ratheesh et $\mathrm{al}^{28}$ who noticed medial thickening in the aorta of cholesterol fed rats.

The migratory and proliferative activities of VSMCs with atherosclerosis are regulated by growth promoters such as platelet derived growth factors (PDGF), endothelin-1 (ET-1), thrombin, fibroblast growth factor (FGF), interleukin-1 (IL-1) and inhibitors such as heparin sulfates, nitric oxide (NO) and 
transforming growth factor (TGF)- $\beta .^{29}$ The matrix metalloproteinases (MMPs) could also participate in the process of VSMCs migration. MMPs could catalyze and remove the external lamina around VSMCs and facilitate contacts with the interstitial matrix. This could promote a change from quiescent, contractile VSMCs to cells capable of migrating and proliferating to mediate repair. ${ }^{30}$ In the current work, in order to show the smooth muscle cell proliferation we performed anti- $\alpha$ smooth muscle actin (anti - $\alpha$ SMA) immunostaining. $\alpha$-SMC is the most abundant cellular protein of SMC and it has been widely used to identify the myofibroblast development in response to injury and in disease. ${ }^{31}$ The current immunohistochemical examination of subgroup II a rats revealed an increased intensity of anti- $\alpha$ smooth muscle actin reaction with appearance of these cells in the intima which went in agreement with the previous histological results. It proved the main role of smooth muscle cell proliferation, migration and increased its synthetic capacity in the development of atherosclerosis.

The current histological changes observed in the hyperlipidemic subgroup using orcein stain were in the form of straightening, disorganization, discontinuation and fragmentation of the elastic lamellae. These findings were in agreement with other authors ${ }^{32}$ who also detected irregular contour of internal elastic lamina in rabbit's ciliary artery after induction of hypercholesterolemia. They explained that it might be a result of irritation by fatty deposits.

It has been also postulated that Fragmentation of elastic lamellae may be due to two concomitant factors. The first factor is the progressive deposition of lipids and calcium salts in the elastic fibers. The second factor is an increase of elastase activity. These two concomitant processes deprive the elastic fibers from their elasticity, and increase their susceptibility to elastolytic enzymes. ${ }^{33}$ The elastolytic process could be required to initiate the atherosclerotic lesion and migration of foam cell from the media through the broken lamina.

On the other hand, the current histological changes using Trichrome stain revealed an evident increase in collagen fibers deposition in the tunica media and adventitia in the aorta of the hyperlipidemic subgroup. In vitro studies have demonstrated that oxidized LDL stimulates the synthesis of collagen by vascular SMCs. ${ }^{34}$ This could be explained by the fact that collagen fibers increase their cross linking and render them resistance to collagenases. This explains the prominence of collagen fibers in aging aorta, the increase of collagen/elastin ratio, as well as the progressive rigidity of the vessels wall. ${ }^{33}$ Cerqueira et $\mathrm{al}^{35}$ reported that the excess deposition or alterations in collagen and elastin leading to increase stiffness were the pathogenic significance in atherosclerosis predisposing to aneurysm formation. This was in accordance with our results which revealed splitting of the wall of the aorta in the hyperlipidemic subgroup. It went also in agreement with Isenburg et $\mathrm{al}^{36}$ who found diminished aortic elastin content with characteristic flattening and fragmentation of the elastic lamellae in experimentally induced abdominal aortic aneurysms.
In the current work, histological and immunohistochemical examination of the aorta of subgroup II b revealed that Inegy administration prevented to a large extent the development of atherosclerotic changes as indicated by a lesser intimal damage, foam cells formation and smooth muscle cells proliferation, these pronounced amelioration in comparison to hyperlipidemic subgroup may be attributed to the effect of statins which can increase endothelial NO production and upregulate endothelial nitric oxide synthase (NOS) expression. $\mathrm{NO}$ is a crucial modulator of vascular damage. It has a number of intracellular effects that lead to vaso-relaxation, endothelial regeneration, reduction of oxidation-sensitive mechanisms and inhibition of leukocyte chemotaxis and platelet adhesion. $^{37}$

$\mathrm{NO}$ is produced from the amino acid L-arginine by nitric oxide synthase (NOS). Inhibition of NO synthesis increases the expression of monocyte chemotactic protein-1 (MCP-1) which is the important promoter of monocyte accumulation in atherosclerosis. Statins also decrease endothelin-1 expression. These factors are favorable to improve endothelial function. It was postulated that statins have anti-atherosclerotic effect related to their NO-stimulatory and/or antioxidant activity independently of its cholesterol-lowering effect. ${ }^{20}$

NO inhibits the proliferation of vascular smooth muscle cells (VSMCs), in part by a cGMP-dependent mechanism, although Na-K-ATPase activity may also be involved. NO also inhibits protein synthesis in VSMCs. ${ }^{38,39}$ This is in accordance with our immunohistochemical result, which reported decreased intensity of anti- $\alpha$ smooth muscle actin reaction in subgroup II b as compared with hyperlipidemic subgroup (subgroup II a).

In a recent study conducted by Vogiatzi and coworkers, ${ }^{23}$ they found that statins, through the increase of catalase and Tetrahydrobiopterin (BH4) levels lead to an increase of NO production and inhibit LDL oxidation, while at the same time restoring vitamin $\mathrm{C}$ and $\mathrm{E}$ levels and endogenous antioxidants such as ubiquinone and glutathione. Vitamins $\mathrm{C}$ and $\mathrm{E}$ are also antioxidants that can inhibit the oxidative process for the prevention of atherosclerotic lesions.

The histological findings in the current study were supported by the biochemical results which showed that ${ }^{[31]}$ P.H. Iverius, The interaction between human plasma lipoproteins and connective tissue glycosaminoglycans, $J$. Biol. Chem. 247 (1972), pp. 2607-2613. View Record in Scopus Cited By in Scopus treatment of HFHC diet fed rats with Inegy markedly decreased serum cholesterol and triglycerides relative to control animals. These findings are in accordance with the result of Rajyalakshmi et $\mathrm{al}^{11}$ who found that HMG-COA reductase inhibitors prevent the progression of hypercholesterolemia during treatment. The reduction of serum cholesterol could be explained by inhibition of cholesterol production in rat liver by blocking HMG-CoA reductase. As a result, hepatocytes become depleted of cholesterol and respond by increasing LDL-C clearance from the blood via up regulation of hepatic LDL-C receptors and decreasing entry of LDL-C into the circulation. These actions, in turn, give rise to lower LDL-C levels. 40 The mechanism of 
plasma triglycerides lowering effect may be due to that simvastatin cause removal of VLDL-TG by increase lipoprotein lipase activity in the tissues. ${ }^{41,42}$

Our recent interest has been focused on strategies that enhance the removal of ROS by using antioxidant. ${ }^{43}$ Recently, much attention has been directed towards the development of ethno-medicines with strong antioxidant properties but low cytotoxicity. $^{44-46}$

Schmidt et $\mathrm{al}^{47}$ reported that cinnamon has a potent antioxidant effect through their study on the composition and antioxidant activities of the essential oil of cinnamon leaves.

In addition to antioxidant effect of cinnamon, it has also anti-hyperlipidemic effect. In the study conducted by Sheng et $\mathrm{al}^{48}$ who found that cinnamon improve lipid profile in high caloric diet that induced obesity in mice. Although no documented histological studies were conducted on the effect of cinnamon on the structure of the aorta, its antioxidant and anti-hyperlipidemic effect made cinnamon a choice of interest in the present study in an attempt to ameliorate the atherogenic effect of HFHC diet.

In the current study, histological, morphometric and immunohistochemical examination of the aorta of subgroup IIb which received both HFHC diet and cinnamon oil revealed amelioration of aortic atherosclerotic changes when compared with the aorta of the hyperlipidemic rats.

The protective activity of cinnamon on atherosclerotic lesion may be attributed to its antioxidant action through their ability to activate the antioxidant enzymes. It was reported by Lee et $\mathrm{al}^{49}$ that cinnamate a phenolic compound in cinnamon increase hepatic catalase (CAT) and glutathione peroxidase (GSH-px) activity. Cinnamate also exert antioxidant through their redox properties which could result in various mechanisms, including: free-radical scavenging activity, transition-metal-chelating and singlet-oxygen-quenching capacity. ${ }^{20}$ These results were in agreement with the results obtained by Anderson et a ${ }^{50}$ who demonstrated how cinnamon served as an important antioxidant.

In the current study, supplementation of cinnamon to the diet had a favorable effect on the lipid profile. It decreased serum cholesterol and triglycerides as compared to the control rats. These findings were in accordance with the study of Kannappan et $\mathrm{al}^{51}$ who reported that cinnamon bark extract prevented the hyperlipidemia in fructose-fed rats due to presence of cinamate compound which inhibit hepatic 5-hydroxy-3-methylglutaryl-coenzyme A (HMG-CoA) reductase activity. A similar result was recorded by Lee et $\mathrm{al}^{49}$ who gave cinnamate $0.1 \%$ for 6 weeks to high cholesterol-fed rats.

Another possible mechanism of hypocholesterolemic effect of cinnamon is its rich source of calcium and fiber, which are both able to bind to bile salts and remove them from the body. When bile is removed, the body must break down cholesterol to make new bile, which can help to lower the cholesterol levels. ${ }^{52}$

In the current study, the previous biochemical and histological results were supported by the current morphometric study, which measured the thickness of tunica intima and media. It revealed a significant increase in thickness in the hyperlipidemic subgroup (subgroup II a) in comparison to control rats. While, in both protected subgroups by Inegy and cinnamon, there was significant reduction in the thickness of tunica intima and media in comparison to subgroup II a.

In the present study, it was found that administration of Inegy and cinnamon oil provided protection against the lipemic-oxidative disorder and act as hypocholesterolemic agents and ameliorated the histological changes induced by hyperlipidemia. Also, it was found that the degree of the protection was the same with both agents. This was confirmed by the statistical and morphometric results which revealed no significant differences between these two subgroups.

\section{Conclusion}

Maintaining a balanced diet and lifestyle are still the most effective means of optimizing cardiovascular health. Choosing an effective combination of nutritional supplements can be an important part of maintaining cardiovascular fitness. Since cinnamon is one of the dietary components that are being used daily in our food products, and it is well known that it is safe for human consumption, we recommend that it can be applied on human volunteer in risk for cardiovascular disease. Cinnamon can be used as a complementary medicine as it has the same effect as an official drug.

\section{Abbreviations}

HFHC: high fat high cholesterol.

\section{Conflict of Interest}

\author{
None declared
}

\section{References}

[1] Farmer JA, Gotto AM. Dyslipidemia and the vulnerable plaque. Prog Cardiovasc Dis. 2002; 44(6): 415-428.

[2] Kwok CY, Wong CNY, Yau MYC, Fu Yu PH, Shan Au AL, Wa Poon CC, et al. Consumption of dried fruit of Crataegus pinnatifida (hawthorn) suppresses high-cholesterol diet-induced hypercholesterolemia in rats. J Funct Foods. 2010; 2: $179-186$.

[3] American Heart Association. American Heart Association Low-Fat, Low-Cholesterol Cookbook, $3^{\text {rd }}$ Edition: Delicious Recipes to Help Lower Your Cholesterol. New York, NY: Clarkson Potter, 2005.

[4] Kosoglou T, Meyer I, Veltri EP, Statkevich P, Yang B, Zhu Y, et al. Pharmacodynamic interaction between the new selective cholesterol absorption inhibitor ezetimibe and simvastatin. Br J Clin Pharmacol. 2002; 54: 309-319.

[5] Shovman O, Levy Y, Gilburd B, Shoenfeld Y. Anti-inflammatory and immunomodulatory properties of statins. Immunol Resp. 2002; 25: 271-285. 
[6] Catapano AL, Catapano L, Fellin R. Intestinal cholesterol absorption: a pharmacological target for lowering of plasma cholesterol. Ital Heart J. 2004; 5(10): 779-84.

[7] Huang JC, Lee TY, Lio MJ, et al. Begin with the real -word patients of non - goal - achieved hypercholesterolemia in Taiwan through the ezetimibe / simvastatin tablet - The BRAVO study. Curr Med Res Opin. 2011; 27(8): 1645-1651.

[8] Garjani A, Fathiazad F, Zakheri A, et al. The effect of total extract of Securigera securidaca L. seeds on serum lipid profiles, antioxidant status and vascular function in hypercholesteremic rat. J Ethnopharmaco. 2009; 126(3): 525-532.

[9] Khan A, Safdar M, Ali Khan MM, Khattak KN, Anderson RA. Cinnamon improves glucose and lipids of people with type 2 diabetes. Diabetes Care. 2003; 26(12): 3215-3218.

[10] Lee YH, Kim MJ, Choi CI, Bae JW, Janh CG, Lee SY. Retrospective study on antihyperlipidemic efficacy and safety of simvastatin, ezetimibe and their combination in Korean adults. Arch Pharm Res. 2011; 34(8): 1331-1337.

[11] Rajyalakshmi G, Reddy A, Rajesham VV. A comparative antihyperlipidemic activity of atorvastatin with simvastatin in rats. The internet journal of pharmacology. 2009: 6(2).

[12] Ghorbani A, Shafiee - Nik R, Rakhshandeh H, Borji A. Antihyperlipidemic effect of a polyherbal mixture in streptozotocin - induced diabetic rats. J Lipids. 2013(2013), Article ID 675759, 6 pages. University press; 1980: 140-222.

[13] Bozzola JJ, Russell LD. Principles and Techniques, Specimens preparation for transmission EM. $1^{\text {st }}$ ed. Boston London: John and Bartlett publishers; 1992: 16-47.

[14] Millonig G. Advantages of a phosphate buffer for OSO4 solutions in fixation. JAPPL Physics. 1961; 32: 1637.

[15] Van Noorden S. Principles in immunostaining. In: Fillip M, Lake B. Histochemistry in pathology. $2^{\text {nd }}$ ed. Edinburgh, London, Melbourne, new York: Churchill livingstone; 1990: 31 .

[16] Shehata A, Yousef O. Physiological studies on the risk factors responsible for atherosclerosis in rat. Nature and Science. 2010; 8(5): 144-151.

[17] EL-Beshbishy HA, Singab AN, Sinkkonen J, Pihlaja K. Hypolipidemic and antioxidant effects of Morus alba L. (Egyptian mulberry) root bark fractions supplementation in cholesterol fed rats. Life Sci. 2006; 78: 2724-2733.

[18] Dimitrova-Shumkovska J, Veenman L, Ristoski T, Leschiner S, Gavish M. Chronic high fat, high cholesterol supplementation decreases $18 \mathrm{kDa}$ translocator protein binding capacity in association with increased oxidative stress in rat liver and aorta. Food Chem Toxicol. 2010; 48: 910-921.

[19] Amin KA, Abd El-Twab TM. Oxidative markers, nitric oxide and homocysteine alteration in hypercholesterolimic rats: role of atorvastatine and cinnamon. Int J Clin Exp. Med 2009; 2: 254-265.

[20] Castillo SS, Doger MM, Bolkent S, Yanardag R. Cholesterol efflux and the effect of combined treatment with niacin and chromium on aorta of hyperlipidemic rat. Mol Cell Biochem.2008; 308: 151-159.
[21] Cooke JP. Role of nitric oxide in progression and regression of atherosclerosis. West J Med. 1996; 164: 419-424.

[22] Vogiatzi G, Tousoulis D, Stefanadis C. The role of oxidative stress in atherosclerosis. Hellenic J Cardiol. 2009; 50: 402-409.

[23] Martinet W, Knaapen MW, De Meyer GR, Herman AG, Kockx MM. Oxidative DNA damage and repair in experimental atherosclerosis are reversed by dietary lipid lowering. Circ Res. 2001; 88: 733-739.

[24] Deepa PR, Varalakshmi P. Atheroprotective effect of exogenous heparin-derivative treatment on the aortic disturbances and lipo-protein oxidation in hypercholesterolemic diet fed rats. Clin Chim Acta. 2005; 355: 119-130.

[25] Mahfouz MM, Kummerow FA. Cholesterol-rich diets have different effects on lipid peroxide-tion, cholesterol oxides, and antioxidant enzymes in rats and rabbits. J Nutr Biochem. 2000; 11: $293-302$.

[26] Kapoor P, Ansari MN, Bhandari U. Modulatory effect of curcumin on methionine-induced hyperlipidemia and hyperhomocysteinemia in albino rats. Indian J Exr Biol. 2008; 46: 534-540.

[27] Ratheesh M, Shyni GL, Sindhu G. Helen A. Inhibitory effect of Ruta graveolens L. on oxidative damage, inflammation and aortic pathology in hypercholesteromic rats. Exp Toxicol Pathol; 2010.

[28] Rudijanto A. The role of vascular smooth muscle cells on the pathogenesis of atherosclerosis. Acta Med Indones. 2007; 39: 86-93.

[29] Sternlicht MD, Werb Z. How matrix metalloproteinases regulate cell behaviour. Annu Rev Cell Dev Biol. 2001; 17 : 463-516.

[30] Jones R, Jacobson M, Steudel W. alpha- smooth muscle cells in pulmonary hypertension. Am J Respir Cell Mol Biol. 1999; 20: 582-594.

[31] Ishikawa H, Uga S, Mashimo K, Yoshitomi T, Kusanagi M, Shimizu K. pharmacological vascular reactivity in isolated hypercholesterolemic rabbit ciliary artery. Exp Eye Res. 2004; 4: 805-813.

[32] Aguila MB, Mandarim CA. Aorta wall quantitative alterations due to different long-term high-fat diet in rats. Food Chem Toxicol. 2003; 41: 1391-1397.

[33] Jimi S, Saku K, Uesugi N, Sakata N, Takebayashi S. Oxidized low density lipoprotein stimulates collagen production in cultured arterial smooth muscle cells. Atherosclerosis. 1995; 116: $15-26$.

[34] Cerqueira N, Yoshida W, Müller S, Sequeira J, Rodrigues A, Padovani C. Morphological and biomechanical study of abdominal aorta of rats submitted to experimental chronic alcoholism. Acta Cir Bra. 2005; 20(3): 213-218.

[35] Isenburg J, Simionescu D, Starcher B, Vyavahare N. Elastin stabilization for treatment of abdominal aortic aneurysms. Circulation. 2007; 115: 1729-737.

[36] Nigris F, Mancini FP, Balestrieri ML, et al. Therapeutic dose of nebivolol, a nitric oxide releasing $\beta$-blocker, reduces atherosclerosis in cholesterol-fed rabbits. Nitric Oxide. 2008; 19: 57-63. 
[37] Vardi N, Ozturk F, Fadillioglu E, Otlu A, Yagmurca M. Histological changes in the rat thoracic aorta after chronic nitric oxide synthase inhibition. Turk J Med Sci. 2003; 33: 141-147.

[38] Hazra B, Biswas S, Mandal N. Antioxidant and free radical scavenging activity of Spondias pinnata. BMC Complement Altern Med. 2008; 8: 63.

[39] Shepherd J. Lipids in health and disease. Biochem Soc Trans. 2004; 32: 1051-1056.

[40] Sato A, Watanabe K, Fukuzumi H, Hase K, Ishida F, Kamei T. Effect of simvastatin (MK-733) on plasma triacylglycerol levels in rats. Biochem pharmacol. 1991; 15; 41(8): 1163-1172.

[41] Suanarunsawat T, Ayutthaya W, Songsak T, Thirawarapan S, Poungshompoo S. Antioxidant effect and lipid lowering effect of essential oils extracted from Ocimum sanctum L. leaves in rats fed with high cholesterol diet. J Clin Biochem Nutr. 2010; 46: $52-59$.

[42] Antoniades C, Tousoulis D, Stefanadis C. Effect of endothelial nitric oxide synthase gene polymorphisms on oxidative stress, inflammatory status and coronary atherosclerosis: an example of transient phenotype. J Am Coll Cardiol. 2007; 49: 1226.

[43] Jovanovic SV, Simic MG. Antioxidants in nutrition. Ann NY Acad Sci. 2000; 899: 326-234.

[44] Li j, Liu T, Wang L, et al. Antihyperglycemic and hyperlipidemic action of cinnamaldehyde in C57BL / Ks db / db mice. J Tradit Chin Med. 2012; 32(3): 446-452.
[45] Kim SH, Choung SY. Antihyperglycemic and hyperlipidemic action of Cinnamomi Cassiae (Cinnamon bark) extract in C57BL / Ks db / db mice. Aech Pharm Res. 2010; 33(2): 325-333.

[46] Schmidt E, Kitzing K, Schloss HA. Composition and antioxidant activities of the essential oil of cinnamon (cinnamomum zeylanicum blume) leaves from sri lanka. Jeobp. 2006; 9(2): 170-182.

[47] Sheng X, Zhang Y, Gong Z, Huang C, Zang YQ. Improved insulin resistance and lipid metabolism by cinnamon extract through activation of peroxisome proliferator-activated receptors. PPAR Res. 2008; 2008: 581348.

[48] Lee JS, Jeon SM, Park EM, et al. Cinnamate supplementation enhances hepatic lipid metabolism and antioxidant defense system. J Med Food. 2003; 6: 183-191.

[49] Anderson RA, Broadhurst CL, Polansky MM, et al. Isolation and characterization of polyphenol type-A polymers from cinnamon with insulin-like biological activity. J Agric Food Chem. 2004; 52(1): 65-70.

[50] Kannappan S, Jayaraman T, Rajasekar P, Ravichandran MK, Anuradha CV. Cinnamon bark extract improves glucose metabolism and lipid profile in the fructose-fed rat. Singapore Med J. 2006; 47(10): 858-863.

[51] Murcia MA, Egea I, Romojaro F, Parras P, Jimenez AM, Martinez- Tome M. Antioxidant evaluation in dessert spices compared with common food additives. Influence of irradiation procedure. J Agric Food Chem. 2004; 52: 1872-1881. 